\title{
Optimization of Sorption Parameters for Color Removal of Textile Dye by Cross-linked Chitosan Beads Using Box- Behnken Design
}

\author{
Ali H. Jawad ${ }^{1, a}$, Nur Shazwani Abdul Mubarak ${ }^{1}$ and W. I. Nawawi ${ }^{1,2}$ \\ ${ }^{1}$ Faculty of Applied Sciences, Universiti Teknologi MARA, 40450 Shah Alam, Selangor, Malaysia \\ ${ }^{2}$ Coal and Biomass Energy Research Group, Faculty of Applied Sciences, Universiti Teknologi MARA, 02600 Arau, \\ Perlis, Malaysia
}

\begin{abstract}
Cross-linked chitosan-epichlorohydrin beads (CEB) was prepared and studied for the removal of Reactive Red 4 (RR4) from textile industry. The effect of parameters such as adsorbent dosage (A: $0.5-1.5 \mathrm{~g} / \mathrm{L}), \mathrm{pH}(\mathrm{B}: 4-10)$ and time of contact (C: 30-80 $\mathrm{min}$ ) on the color removal of RR4 was investigated using response surface methodology (RSM) based on Box-Behnken surface statistical design at an initial RR4 concentration, Co $=100 \mathrm{mg} / \mathrm{L}$ as a fixed input parameter. The results of RSM indicated that the proposed model predicted the responses adequately within the limits of input parameters being used. Regression analysis showed good fit of the experimental data to the second-order polynomial model with coefficient of determination $\left(\mathrm{R}^{2}\right)$ value of 0.9958 and Fisher F-value of 185.36. Optimization of adsorbent dose (1.0 g/L), $\mathrm{pH}(4.0)$, and contact time $(80 \mathrm{~min})$ gave a maximum of $70.53 \% \mathrm{RR} 4$ removal by CEB.
\end{abstract}

\section{Introduction}

Colored effluents from textile industries contain several types of synthetic dyestuffs [1]. These dyes are considered hazardous, toxic, and non-biodegradable and tend to suppress photosynthetic activity in aquatic systems by preventing the penetration of sunlight and oxygen. Therefore it posed a serious environmental problem and direct destruction to the aquatic system when discharged into water stream $[2,3]$. Among the various treatments of effluents that contain dyes, the adsorption method is the best alternative and has been widely used to remove pollutants from effluents [4] because of its high performance, flexibility and simplicity of design, convenience of operation, and selectivity [5]. Adsorption also does not result in formation of harmful by-products [6]. Chitosan is an abundant cationic biopolymer produced through a deacetylation process of the naturally occurring biopolymer chitin [7]. Chitosan is an excellent material compared to other polyssacharides due to the presence of active adsorption sites such as amino $\left(-\mathrm{NH}_{2}\right)$ and hydroxyl $(-\mathrm{OH})$ groups. Unfortunately, drawbacks of natural chitosan such as low mechanical properties, high swelling and shrinkage index, compressible at high operating pressure, and soluble in many organic acids limits the adsorption process [8]. Therefore, chemical modification through a cross-linking process is an important step to enhance the mechanical resistance, stabilize chitosan at low drastic $\mathrm{pH}$ and increase the adsorption

\footnotetext{
${ }^{a}$ Corresponding author : ali288@perlis.uitm.edu.my
} 
abilities of chitosan [9]. The application of chitosan and its cross-linked derivatives in the form of flakes and/or powder is significantly limited in scaling up the adsorption system for industrial applications due to its small size particle that leads to serious clogging effect [10]. Therefore formation of chitosan beads together with crosslinking reaction can enhance the diffusion mechanism and improve the access to internal adsorption sites.

The application of experimental design such as response surface methodology (RSM) was employed which result in improved decolorization and the most importantly can reduce the process variability, cost and time consuming [11]. In addition RSM can be applied in different types of disciplined and provides a maximum number of information with a minimal number of experiments. Moreover, the classical way of changing one variable at a time and keeping the others constant are incapable of revealing the optimal combination of the parameters involved [12]. Thus, the present study aims to prepare cross-linked chitosan-epichlorohydrine beads (CEB) as a promising synthetic biopolymer for removal of reactive dyes from polluted water by using three level factorial of BoxBehnken design (BBD). The effect of operational parameters such as adsorbent dosage, $\mathrm{pH}$ and contact time of CEB for the removal of RR4 dye were evaluated and optimized. Reactive red 4 (RR4) was chosen as a model pollutant because it facilitates electrostatic interaction between polymer chain and the negatively charged anionic dye.

\section{Material and Methods}

Crosslinked chitosan-epichlorohydrine beads (CEB) of particles size $(<250 \mu \mathrm{m})$ was prepared according to the same procedure described previously [13]. Reactive Red 4 (RR4) or otherwise commonly known as Cibacron Brilliant Red (Colour Index Number: 18105, chemical formula: $\mathrm{C}_{32} \mathrm{H}_{23} \mathrm{ClN}_{8} \mathrm{Na}_{4} \mathrm{O}_{14} \mathrm{~S}_{4}, \mathrm{MW}: 995.23 \mathrm{gmol}^{-1}$, and with $50 \%$ dye content was chosen as adsorbate. The stock solution of RR4 was prepared $(1000 \mathrm{mg} / \mathrm{L})$, and the desired concentration can be obtained by diluting stock solution with ultrapure water $\left(18.2 \mathrm{M} \Omega \mathrm{cm}^{-1}\right)$. Initial $\mathrm{pH}$ of the RR4 solution was adjusted with $0.1 \mathrm{~mol} / \mathrm{L} \mathrm{HCl}$ or $0.1 \mathrm{~mol} / \mathrm{L} \mathrm{NaOH}$ using a Metrohm, $827 \mathrm{pH}$ lab. Colour removal was determined by using a direct reading spectrophotometer (DR $2800 \mathrm{HACH}, \mathrm{USA}$ ) at $\lambda_{\max } 517 \mathrm{~nm}$. The percentage of RR4 colour removal in the aqueous solutions by CEB was calculated by the following Equation (1):

$$
\text { Color removal }(\mathrm{CR} \%)=\left(\mathrm{C}_{\mathrm{o}}-\mathrm{C}_{\mathrm{t}} / \mathrm{C}_{\mathrm{o}}\right) \times 100
$$

where $\mathrm{C}_{\mathrm{o}}$ and $\mathrm{C}_{\mathrm{t}}$ both in $(\mathrm{mg} / \mathrm{L})$ are, respectively, the initial and remaining concentration of RR4 in solution at time $\mathrm{t}(\mathrm{min})$.

In the present study, the 3-level, 3-factor Box-Behnken experimental design is applied to investigate and validate adsorption process parameters affecting the removal of RR4 dye by CEB. Adsorbent dose (A: 0.5-1.5 g/L), $\mathrm{pH}(\mathrm{B}: 4-10)$ and time of contact (C: 30-80 min), while dye concentration of $100 \mathrm{mg} / \mathrm{L}$ was kept as a constant input parameter. A total of 17 experiments have been conducted in this work to evaluate the effects of the three main independent parameters on the removal of RR4 dye. The actual experimental design matrix is given in Table 1. The results were analyzed using the coefficient of determination $\left(\mathrm{R}^{2}\right)$, Pareto analysis of variance (ANOVA) and statistical and response plots.

\section{Results and Discussion}

The statistical significance of the BBD model was assessed by analysis of variance (ANOVA). The results of second-order response surface model in the form of analysis of variance (ANOVA) are shown in Table 2. Values of model terms Prob $>\mathrm{F}<0.0500$ designate that factors are significant under selected conditions. Significant model terms for response (RR4 removal \%) are A, B, C, AB, AC, A ${ }^{2}$, $\mathrm{B}^{2}$, and $\mathrm{C}^{2}$, whereas another remaining term $\mathrm{BC}$ had less significance for the response and can be 


\section{IConCEES 2015}

neglected to improve the model and thus the equation developed is expressed by the following Equation (2):

$$
\mathrm{CR} \%=+51.69+10.13 \mathrm{~A}-13.80 \mathrm{~B}+10.78 \mathrm{C}-5.15 \mathrm{AB}+2.93 \mathrm{AC}-12.85 \mathrm{~A}^{2}-6.20 \mathrm{~B}^{2}+1.90 \mathrm{C}^{2}
$$

The goodness of fit of the model was also tested by the multiple correlation coefficients $\left(R^{2}\right)$. In this case, the value of the multiple correlation coefficients was 0.9958 , which implied that this regression is statistically significant. This can be observed in Figure 1 by comparing the actual values against the predicted responses by the model for the percentage of RR4 removal. The value of predicted multiple correlation coefficient (pred. $R^{2}=0.8778$ ) is in reasonable agreement with the value of the adjusted multiple correlation coefficient (adj. $\left.R^{2}=0.9527\right)$. The individual effect of the studied variables including adsorbent dosage (A), $\mathrm{pH}(\mathrm{B})$, contact time (C) and color removal efficiency (\%) was investigated by perturbation plots as shown in Figure 2. The steep curvature in A curve indicates that the color removal was sensitive to this variable. The relatively sharp line of $\mathrm{C}$ shows the high sensitivity to change in operation time levels. The $\mathrm{pH}$ curve shows a slow curvature indicating that this factor has slight effect on the response. From Figure 2, it can be seen that the RR4 dye color removal efficiency increases as the adsorbent dosage increases and decreases with increasing $\mathrm{pH}$.

Table 1. The 3-factors BBD matrix and the value of the response function (color removal, CR (\%)).

\begin{tabular}{cccccc}
\hline Run & $\begin{array}{c}\text { Adsorbent dose } \\
\text { (g/L) }\end{array}$ & $\mathbf{p H}$ & Time (min) & \multicolumn{2}{c}{$\mathbf{C R \%}$} \\
\hline 1 & 0.5 & 4 & 55 & 31.28 & Actual \\
2 & 1.5 & 4 & 55 & 60.19 & 61.72 \\
3 & 0.5 & 10 & 55 & 15.40 & 13.87 \\
4 & 1.5 & 10 & 55 & 23.69 & 23.81 \\
5 & 0.5 & 7 & 30 & 20.95 & 22.76 \\
6 & 1.5 & 7 & 30 & 37.00 & 37.16 \\
7 & 0.5 & 7 & 80 & 38.63 & 38.47 \\
8 & 1.5 & 7 & 80 & 66.39 & 64.58 \\
9 & 1.0 & 4 & 30 & 53.28 & 51.59 \\
10 & 1.0 & 10 & 30 & 21.92 & 21.64 \\
11 & 1.0 & 4 & 80 & 70.53 & 70.81 \\
12 & 1.0 & 10 & 80 & 43.85 & 45.54 \\
13 & 1.0 & 7 & 55 & 51.08 & 51.69 \\
14 & 1.0 & 7 & 55 & 51.99 & 51.69 \\
15 & 1.0 & 7 & 55 & 52.26 & 51.69 \\
16 & 1.0 & 7 & 55 & 51.72 & 51.69 \\
17 & 1.0 & 7 & 55 & 51.40 & 51.69 \\
\hline
\end{tabular}


Table 2. Analysis of variance (ANOVA) for response surface quadratic models.

\begin{tabular}{cccccc}
\hline Source & Sum of Squares & df & Mean Square & F Value & p-value Prob $>$ F \\
\hline Model & 4318.32 & 9 & 479.81 & 185.36 & $<0.0001$ \\
A-Adsorbent dose & 820.33 & 1 & 820.33 & 316.91 & $<0.0001$ \\
B-pH & 1524.07 & 1 & 1524 & 588.79 & $<0.0001$ \\
C-Time & 929.88 & 1 & 929.88 & 359.24 & $<0.0001$ \\
Adsorbent dose x pH & 106.3 & 1 & 106.3 & 41.06 & 0.0004 \\
Adsorbent dose x Time & 34.28 & 1 & 34.28 & 13.24 & 0.0083 \\
pH x Time & 5.48 & 1 & 5.48 & 2.12 & 0.1892 \\
Adsorbent dose ${ }^{2}$ & 695.39 & 1 & 695.39 & 286.65 & $<0.0001$ \\
pH $^{2}$ & 161.79 & 1 & 161.79 & 62.5 & $<0.0001$ \\
Time $^{2}$ & 15.56 & 1 & 15.56 & 5.9 & 0.0456 \\
Residual $_{\text {Core Total }}^{18.12}$ & 7 & 2.59 & & \\
\hline
\end{tabular}

ANOVA results for the response parameter (Table 2) indicated that the maximum RR4 removal $(\%)$ can be obtained under following interaction terms: $\mathrm{AB}$ and AC. Figures 3 and 4 show the three dimensional (3-D) and contour plots of the response at the optimal interaction terms of $\mathrm{AB}$ and $\mathrm{AC}$ respectively, and simultaneously keeping other two variables constant at central level. The combined effect of adsorbent dose (A) and pH (B) on RR4 removal efficiency is shown in 3-D plot of Figure 3. In fact, adsorbent dose reflects the capability of the CEB adsorbent to uptake the RR4 molecules from a given solution, while initial solution $\mathrm{pH}$ is responsible for surface charge of adsorbent, hence their interaction effect is influential in the model.

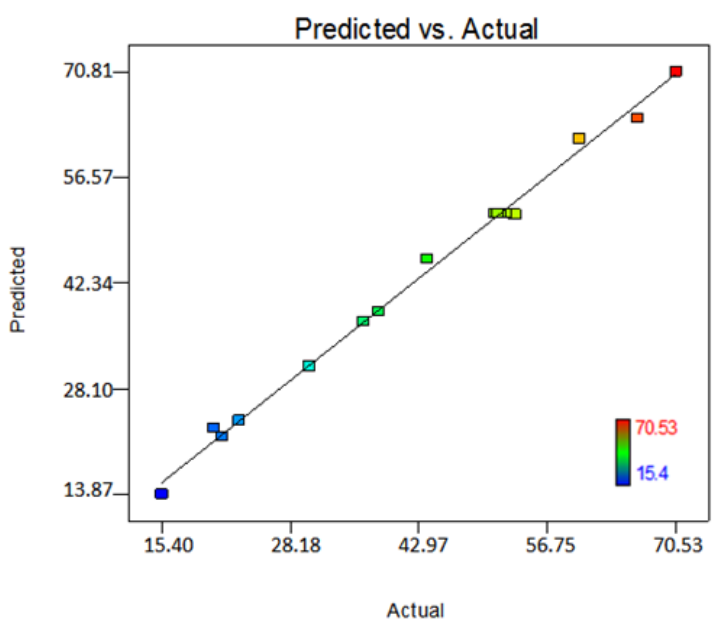

Figure 1. Comparison of actual results of RR4 removal $\%$ with the predicted values by $\mathrm{BBD}$ model.

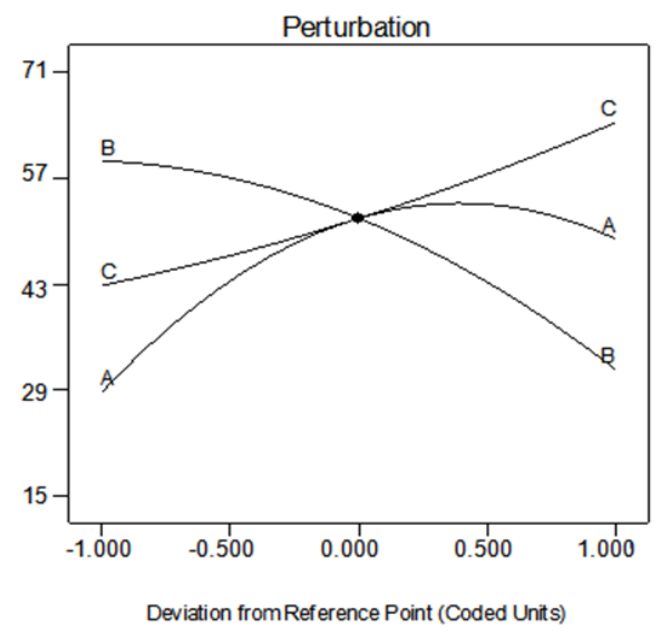

Figure 2. Perturbation plots for the removal of RR4 using CEB. 


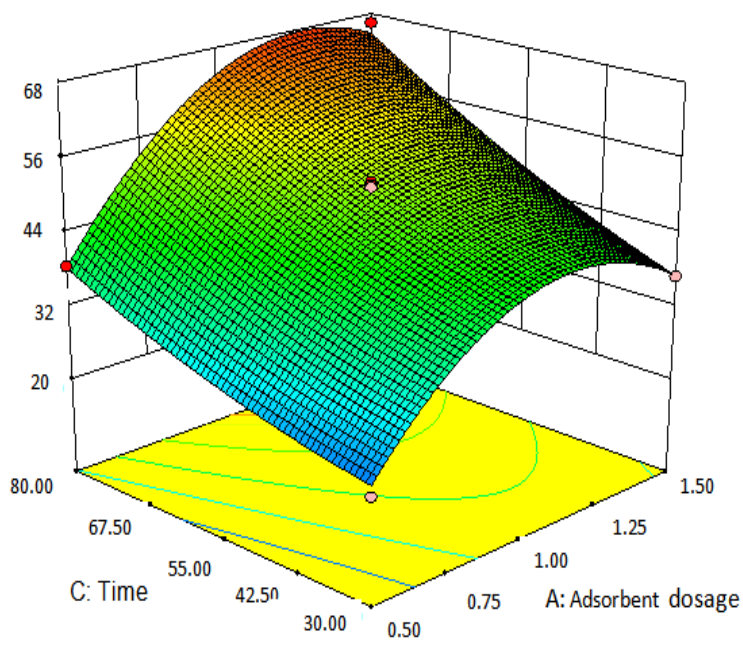

Figure 3. The 3-D response surface of the RR4 removal efficiency as the function of adsorbent dose and $\mathrm{pH}[\mathrm{RR} 4]_{\mathrm{o}}=100 \mathrm{mg} / \mathrm{L}$ and agitation time $=$ $55.00 \mathrm{~min})$.

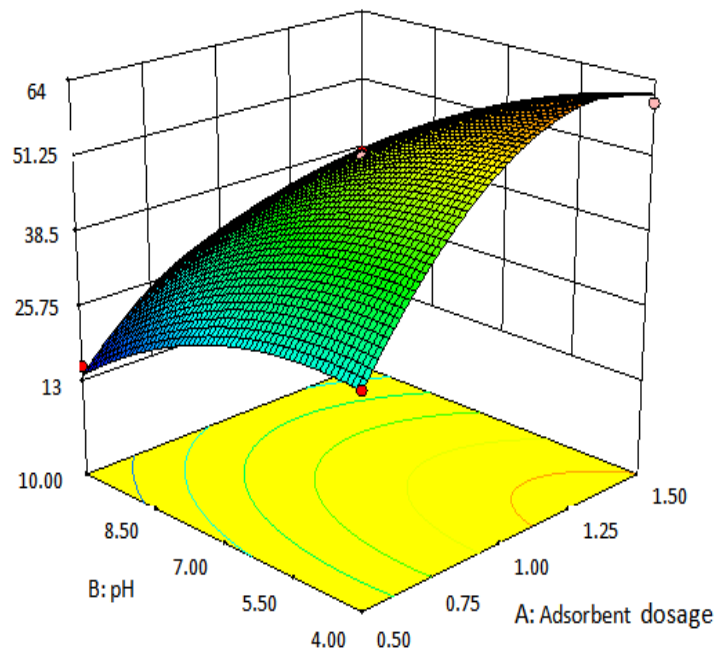

Figure 4. The 3-D response surface of the RR4 removal efficiency as the function of adsorbent dose and agitation time $[\mathrm{RR} 4]_{\mathrm{o}}=100 \mathrm{mg} / \mathrm{L}$ and $\mathrm{pH}=7.00)$.

As for $\mathrm{pH}$, the explanation of this phenomenon is that the hydrogen atom $\left(\mathrm{H}^{+}\right)$available in the solution could protonate the amine groups $\left(-\mathrm{NH}_{2}\right)$ of chitosan. Consequently, the surface of the CEB would be positively charged, especially in acidic environment at $\mathrm{pH}$ lower than 6.5 , as expressed by Equation (3).

$$
\mathrm{R}-\mathrm{NH}_{2}+\mathrm{H}^{+} \leftrightarrow \mathrm{R}-\mathrm{NH}_{3}^{+} \quad(\mathrm{pH}<6.5)
$$

In addition, the intensity of the positive charge on the chitosan polymeric surface can be increased by decreasing the $\mathrm{pH}$ value and making the sorption process $\mathrm{pH}$ sensitive [14]. The combined effect of (A) and (C) on RR4 removal efficiency is shown in 3-D of Figure 4. Time of contact offers better contact between the RR4 and CEB. As can be seen, the RR4 removal efficiency increases up to 70.53 $\%$ by increasing time of contact and CEB dose simultaneously. However, it was also observed that there is no remarkable change in RR4 removal after reaching $1 \mathrm{~g} / \mathrm{L} \mathrm{CEB}$ adsorbent dose even with longer contact time.

\section{Conclusion}

In this work, the feasibility of color removal of RR4 onto CEB as a biosorbent was investigated. RSM and BBD were appreciable in determining the optimal conditions for color removal such as adsorbent dose, $\mathrm{pH}$ and contact time. The results obtained indicated that maximum RR4 color removal of $70.53 \%$ by CEB can be achieved at adsorbent dose $(1.0 \mathrm{~g} / \mathrm{L}), \mathrm{pH}$ (4.0), and contact time (80.0 $\mathrm{min})$.

\section{References}

[1] B. Balci, O. Keskinkan, M. Avci, Expert Systems with Applications, 38, 949-956, (2011).

[2] R. Huang and Q. Liu, Arabian J. Chem, (2013), online available 17.05.2013: http://dx.doi.org/10.1016/j.arabjc.2013.05.017 
[3] L.Wang, J. Li, Ind. Crop Prod., 42, 153-158, (2013).

[4] M. Vakili, M. Rafatullah, B. Salamatinia, A.Z. Abdullah, M.H. Ibrahim, K.B. Tan, Carbohydr Polym., 113, 115-130, (2014).

[5] M. Rafatullah, O. Sulaiman, R. Hashim and A. Ahmad, J. Hazar. Mater., 177, 70-80, (2010).

[6] C. Crini and P.M. Badot, Prog. Polym. Sci., 33399-447, (2008).

[7] A.C. Rodrigues, M. Boroski and N.S. Shimada, J. Photochem. Photobiol., A 194, 1-10, (2008).

[8] W.S.W. Ngah, C.S. Endud and R. Mayanar, React. Funct. Polym., 50,181-190, (2002).

[9] J. Wang and C. Chen, Bioresour. Technol., 160, 129-141, (2014).

[10]K. Papadopoulou, I.M Kalagona, A. Philippoussis and F. Rigas, Int. Biodet and Biodeg., 77,3138, (2013).

[11]P. Sharma, H. Kaur and M. Sharma, Environ. Monit. Assess., 183, 151-195, (2011).

[12] A.A. Oladipo, M. Gazi, E. Yilmaz, Chem. Eng. Res. Design, 104, 264-279, (2015).

[13] W.S.W. Ngah, S.A. Ghani and A. Kamari, Bioresour. Technol., 96, 443-450, (2005).

[14] S. Chatterjee, B.P. Chatterjee, A.R. Das and A.K. Guha, J. Colloid Interface Sci., 288, 30-35, (2005). 